\title{
AC 2012-3865: AN INTERACTIVE K-12 ENGINEERING CURRICULUM DEVELOPMENT ON RENEWABLE SOURCES AND ENERGY STORAGE AND IN POWER SYSTEMS
}

\section{Jana Sebestik, University of Illinois, Urbana-Champaign}

Jana Sebestik received a B.S. in mathematics and M.Ed. in mathematics education from the University of Illinois, Urbana-Champaign. She has 34 years of classroom experience teaching mathematics in grades 7-12. She is currently a curriculum specialist at the Office for Mathematics, Science, and Technology Education (MSTE) in the College of Education at the University of Illinois, Urbana-Champaign, and Education Lead for Trustworthy Cyber Infrastructure for the Power Grid (TCIPG). MSTE works with mathematics and science teachers to integrate technology into K-12 classrooms. TCIPG is addressing the challenge of how to protect the nation's power grid by significantly improving the way the power grid infrastructure is built, making it more secure, reliable, and safe.

\section{Mr. Quanyan Zhu, University of Illinois, Urbana-Champaign}

Quanyan Zhu is currently a Ph.D. candidate at the Department of Electrical and Computer Engineering and the Coordinated Science Laboratory (CSL) at University of Illinois, Urbana-Champaign (UIUC), working with Prof. Tamer Bacsar at the Information Trust Institute (ITI). He has received his master's and bachelor's degrees from University of Toronto and McGill University, respectively and both in electrical engineering. He has been a visiting researcher at University of Waterloo, University of Avignon, University of Houston, INRIA-Sophia Antipolis, Idaho National Laboratory and SUPELEC. He is interested in problems at the interface of the cyber and physical worlds and uses tools such as optimal/stochastic control, reinforcement learning, statistical mechanics and game theory to deal with security and resilience issues in communication networks, biological systems, smart grids, and control systems. He is the author of the book "Game-Theoretical Modeling of WDM Optical Networks: Design, Analysis and Algorithms." $\mathrm{He}$ is a recipient of NSERC Canada Graduate Scholarship, University of Toronto Fellowship, Ernest A. Reid Fellowship, and Mavis Future Faculty Fellowships. 


\title{
An Interactive K-12 Engineering Curriculum on Renewable Sources and Energy Storage in Power Systems
}

\begin{abstract}
:
The success of modernizing the U.S. electrical grid depends on research, engineering, and policy, but also, on the education and acceptance of electricity consumers. In this paper we introduce K-12 power engineering education curriculum material that focuses the benefits and challenges that come with integrating renewable resources and the impact of energy storage technology. The curriculum aims to provide information about current and future electricity generation and delivery systems and to engage students who may pursue careers in related industries.

An interactive Java applet (see Fig. 1) and related lessons allow students to explore effects on the power system as communities demand more power and wind generation is added or increased. They can also investigate how the availability of large-scale energy storage allows for the efficient use of intermittent energy sources like wind and solar. The simulation helps students understand some of the complexities of the power grid of the future. The lessons allow students to compare residential, commercial and industrial demand and to consider how past behaviors allow power professionals to predict future use. Students can consider wind variability, transmission needs, system costs and $\mathrm{CO}_{2}$ emissions, and how the availability of energy storage may impact the system.
\end{abstract}

The course materials have been used successfully in classrooms and in community events throughout the nation. During the past year, there were over 24,000 visits to the websites associated with the curriculum. Teachers from several states have adopted the materials for their classes. Power utilities and environmental groups are also interested in our materials for customer education. The materials are available from the project website. ${ }^{2}$

This paper provides examples of the materials and discusses the major engineering concepts associated with them. We also discuss our continuing efforts to disseminate these materials to educators around the world and outline future plans for further development and dissemination.

\footnotetext{
1 tcipg.org

2 tcipg.mste.illinois.edu
} 


\section{Introduction and Motivation}

Recent media attention has increased awareness of the need for an intelligent, resilient, cyber secure electricity production and delivery system. This vision has come to be known as the "smart grid." Illinois researchers, as part of a large research program, Trustworthy Cyber Infrastructure for the Power Grid ${ }^{1}$ (TCIPG), are working with others at Dartmouth College, Cornell University, University of California at Davis, and Washington State University to protect the nation's power grid by significantly improving the infrastructure, making it more secure, reliable, and safe.

TCIPG educators and researchers have developed five interactive Java applets ${ }^{2}$ and curriculum materials, appropriate for middle school grades and higher, that involve young people in virtual power systems simulations. The curriculum provides information about current and future electricity generation and delivery systems and engages students who may pursue careers in related industries. These materials have been used successfully in classrooms and in community events throughout the nation. During the past year there were over 24,000 visits to these websites. Teachers from several states have contacted us as they use the materials with their students. Power utilities and environmental groups have asked permission to use our materials to educate their customers. The Department of Energy's Office of Electricity Delivery and Energy Reliability has featured the applets and lessons on their website ${ }^{3}$. Engineers, as a group, are interested and involved in education in their local communities. They have used our materials as resources to help educate children and the public at large about the important work they are doing. Our materials have been popular with visitors of all ages at Illinois's College of Engineering's annual Engineering Open House.

To facilitate greater understanding of existing and emerging issues related to the design and operation of the power grid, the authors have worked over the past several years to develop a suite of interactive, visually compelling lessons accompanied by student and teacher resources [1]-[3]. Interactive lessons foster engagement and learning and have been shown to be effective for engineering design projects [4], computer-aided design [5], acoustics [6], and has been particularly effective in engaging women and minority students [7]. Supplementing the interactive applets with supporting print materials for both students and teachers is also a key component. This changes the activity from a less-effective "pure discovery" [8] methodology, in which students are asked to extract meaning on their own, to the more-effective "guided discovery" [9], in which students' explorations are assisted by expert advice in the form of teacher instruction along with supplementary written and audiovisual material.

\footnotetext{
${ }^{3}$ http://energy.gov/oe/interactive-grid
} 


\section{Wind and Storage Curriculum}

Increasing the amount of electricity generated from renewable energy sources has become a major policy priority for many countries around the world, and wind and solar are providing more energy every year. These resources are domestic and do not rely on fossil fuels, but come with potential challenges. To help students (and the public at large) better understand some of these challenges, we have developed a set of interactive lessons focused on the integration of wind generation into the power grid.

The curriculum explores issues related to generation, demand, and transmission of electricity. When the applet opens, a coal powered generator and a natural gas generator are available to deliver electricity to three communities, but only the coal generator is producing. The wind farm is not yet connected to the system. As the demand from the communities changes over a 24-hour period, the generators adjust their power production. Fuel costs and carbon dioxide $\left(\mathrm{CO}_{2}\right)$ emissions per hour for each of the generators is shown. The total peak demand for the communities is set to be $750 \mathrm{MW}$. There are buttons for plotting graphs that show costs, emissions, available wind power, branch flow, load and generation.

To help students to explore the complex power grid of the future, the simulation includes the following components (see Fig. 1):

- Residential, commercial, and industrial load centers that each illustrate typical daily load variations

- Coal and natural gas facilities that represent established generation resources. Each has a capacity of $1500 \mathrm{MW}$

- A wind farm with output power that follows a daily pattern based on measured wind speed data

- A storage device with $100 \mathrm{MW}$ capacity and energy limitation of $1000 \mathrm{MWh}$

- Transmission lines connecting these components

- Three system parameters can be changed interactively by manipulating sliders on the main applet window:

Peak community power demand: demand at each of the three load centers can be scaled so that the peak demand varies from 250 to $5000 \mathrm{MW}$.

Wind power capacity: the maximum output of the wind farm, corresponding to the period of peak wind speed on the system, can be scaled from $195 \mathrm{MW}$ to $3902 \mathrm{MW}$. 
Capacity of the transmission line from Substation 1 to Substation 2: this transmission line connects the wind farm and the storage device to the load

Examples of challenge questions from the student pages are below:

- Watch the clock and notice how the demand from the communities changes throughout the day. What do you see? At what times is the power demand from the residential load lowest? When is it highest? At what times are the power demands from the commercial load and industrial load lowest and highest?

- The power utility wants to provide electricity to its customers at the lowest cost. It is also concerned about climate change and wants to keep its $\mathrm{CO}_{2}$ emissions as low as possible, so it wants to add wind power generation. The site with good wind resources is some distance from the communities so the utility needs transmission lines to connect to it. Click on the switch to close the line between substation 1 and substation 2 . How much power does the wind farm contribute to the communities? How does this affect the costs and emissions?

- Notice the slider for Wind farm capacity. The wind farm's capacity is 195 MW when the applet opens. This slider sets the maximum power the wind farm can produce under perfect wind conditions. The power utility could increase the wind farm capacity by building more turbines. What changes when you move this slider? How does the plot showing system costs change when wind is added to the system?

- The utility wants to be prepared for the peak community demand to increase to $1250 \mathrm{MW}$ in the near future. It also wants to optimize wind power generation and keep $\mathrm{CO} 2$ emissions below 1000 tons $\mathrm{CO} 2 / \mathrm{hr}$. What is the ideal size for the trans- mission line from substation 1 to 2 if the wind farm capacity re- mains at 195 MW? Close the line between Substation 1 and the Storage Device. How does the availability of storage affect the needed transmission line size?

\section{Outreach Efforts and Social Impact}

\section{A. Web accessible}

To ensure that the developed materials reach the widest possible audience, all of the lessons are freely available from the University of Illinois's Office of Mathematics, Science, and Technology Education (MSTE) website. We also maintain an up-to-date collection of the applets for offline usage.

\section{B. Museum exhibit}


We have been collaborating with the Orpheum Children's Science Museum in Champaign, IL on an exhibit entitled "Mission Smart Grid" (See Fig. 2). Museum visitors are invited to become members of the "Smart Grid Tech Force" and are offered a mission related to securing the power grid. Tech Force candidates visit various training centers and workshop areas located throughout the museum to learn about electricity production and transmission. The main "Control Center" is a 72 in. SMARTboard that features the interactive lessons developed by our team.

\section{Project Lead the Way Curriculum}

Project Lead the Way, the largest non-profit provider of science, technology, engineering, and mathematics education programs, has incorporated these interactive lessons into its most recent middle school curriculum [10]. In 2010, twenty-three affiliate universities, representing as many states, offered Project Lead the Way's two-week summer professional development institutes for middle school teachers introducing the new Energy and the Environment module. Students at approximately 1000 middle schools are receiving this curriculum beginning in the 2010-2011 school year. The Energy and Environment module continues to be offered at PLTW summer institutes.

\section{Conferences and Public Workshops}

Reaching students directly can be difficult, so another major component of our outreach efforts is to take the lessons we have developed to math and science teacher conferences and get teachers engaged in this area. The lessons have also been demonstrated in a variety of public forums, such as the University of Toronto Sustainable Energy Fair.

\section{E. Measuring Success}

Because of the many different avenues through which we distribute the work described here, developing effective metrics for success is challenging. Because the free accessibility of the materials is a key aspect of our work, we use detailed weekly and monthly reports to gauge the impact of the materials. Since its inauguration, 50, 609 people have visited our web site, among which 34,609 are unique visitors. Fig. 3 shows the number of visitors from Jan. 10, 2011 to Jan. 10, 2012 in the past year. In Table 1 and Table 2, we show the statics on domestic and international web access, respectively.

We are also working to develop a more formal method of evaluating the impact of the lessons on student learning, but these efforts are still at the planning stage.

As future work, we intend to develop more interactive and enjoyable applets for students to merge in the learning environment. One of the prospective topics is to use a game-based applet to illustrate multi-user demand response. Students can use the control panel on their loaded program to choose strategically appliances to turn on/off and the level of storage and renewable energy generation at each household. The decisions made by students will affect the market price due to the balance of 
supply and demand. Hence one student's electricity consumption can influence the electricity bill of the others through the market price. Students are told to minimize their electricity bill and maximize their energy efficiency. The goal of the game is to show (1) how the market works due to the relation of supply and demand, (2) how renewable energies, storage and real-time pricing can help save energy and increase energy efficiency. Students can learn and interact with each other using this applet. This can provide students a higher-level picture of the power system and market. A sketch of the applet between two students A and B is illustrated in Fig. 5.



Peak community
power demand: $750 \mathrm{MW}$

Fig. 1 Simulation environment for wind and storage interactive lessons 


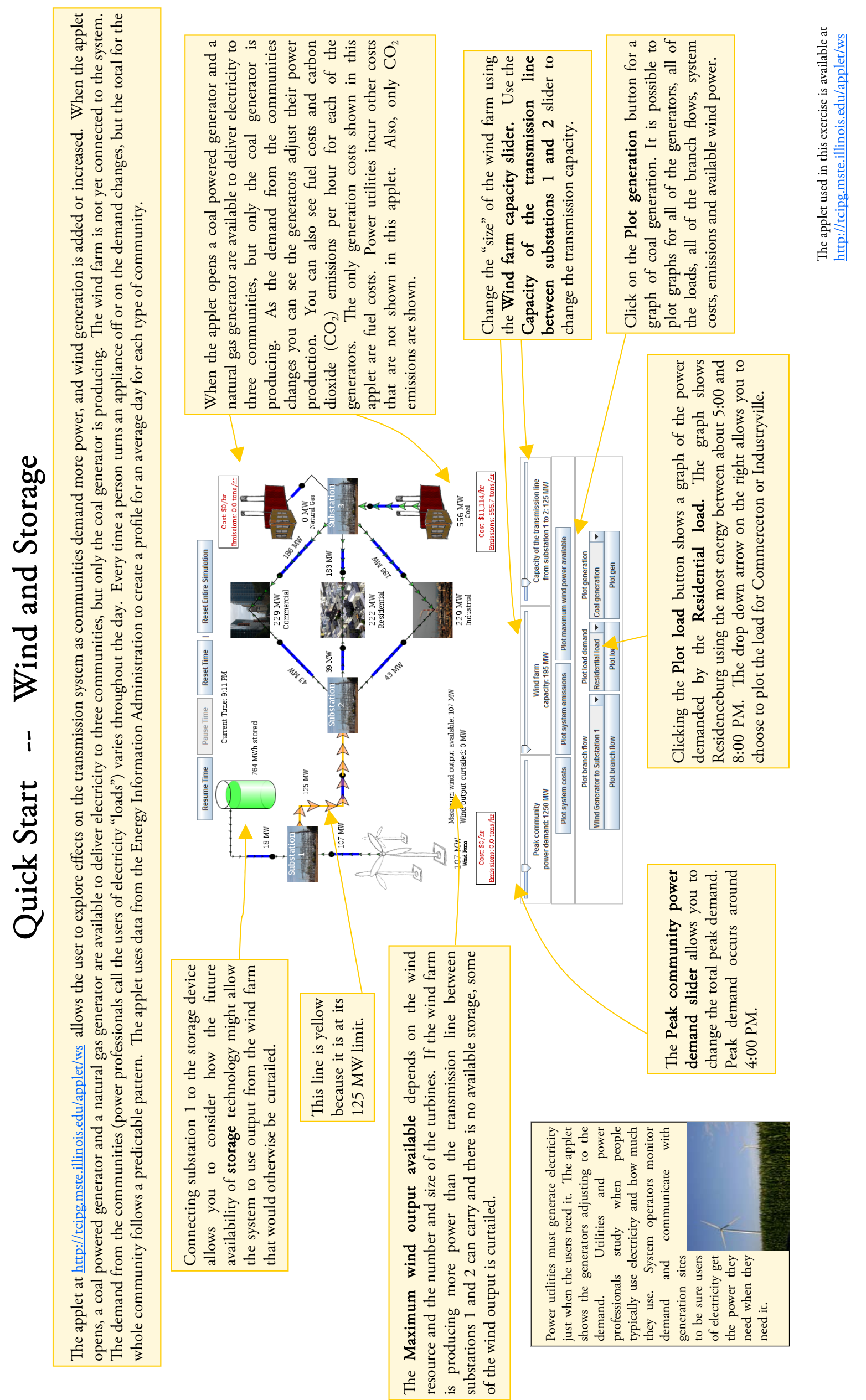

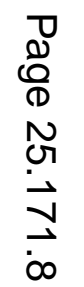




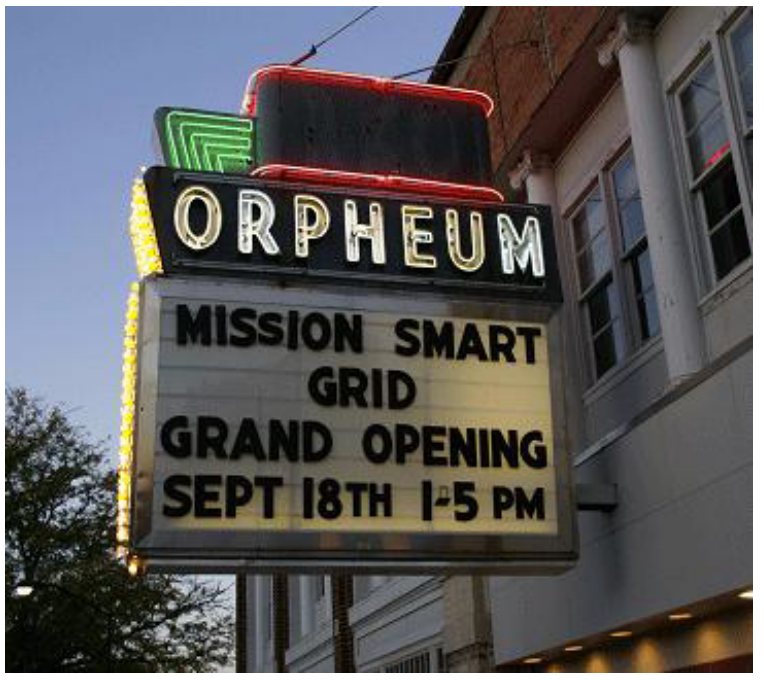

Fig. 3 The Orpheum children's museum's “Mission Smart Grid” exhibit

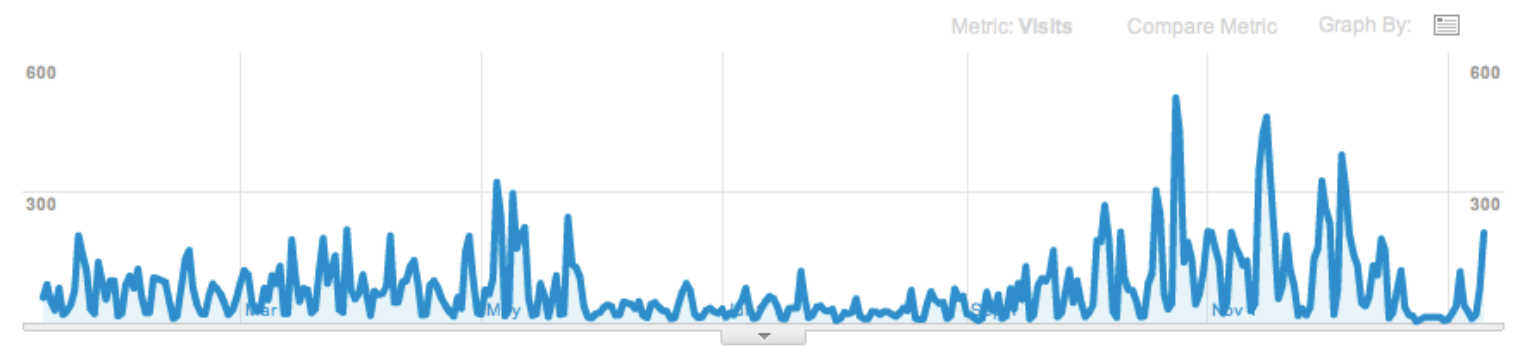

Fig. 4 Number of visitors from Jan. 10, 2010 to Jan. 10, 2011.

\begin{tabular}{|l|l|r|r|r|r|r|}
\hline \multicolumn{2}{|l|}{ Region } & Visits & $\downarrow$ & Pages Nisit & \multicolumn{2}{c|}{$\begin{array}{c}\text { Avg. Time on } \\
\text { Site }\end{array}$} \\
\hline 1. & Illinois & $\mathbf{2 , 3 7 9}$ & 2.93 & $00: 04: 37$ & $47.58 \%$ & $46.70 \%$ \\
\hline 2. & Pennsylvania & $\mathbf{2 , 3 2 5}$ & 2.13 & $00: 03: 50$ & $69.38 \%$ & $58.45 \%$ \\
\hline 3. & Maryland & $\mathbf{1 , 7 3 9}$ & 2.45 & $00: 04: 31$ & $61.36 \%$ & $39.39 \%$ \\
\hline 4. & New York & $\mathbf{1 , 6 0 7}$ & 2.58 & $00: 04: 37$ & $66.15 \%$ & $46.55 \%$ \\
\hline 5. & Minnesota & $\mathbf{1 , 5 1 0}$ & 3.19 & $00: 05: 50$ & $64.90 \%$ & $43.51 \%$ \\
\hline 6. & Ohio & $\mathbf{1 , 4 9 2}$ & 2.67 & $00: 03: 43$ & $57.04 \%$ & $52.88 \%$ \\
\hline 7. & California & $\mathbf{1 , 4 2 7}$ & 2.63 & $00: 04: 18$ & $75.68 \%$ & $50.88 \%$ \\
\hline 8. & Washington & $\mathbf{1 , 3 3 6}$ & 2.38 & $00: 03: 33$ & $90.87 \%$ & $64.45 \%$ \\
\hline 9. & Texas & $\mathbf{1 , 2 1 8}$ & 3.09 & $00: 05: 14$ & $61.90 \%$ & $44.58 \%$ \\
\hline 10. & Michigan & $\mathbf{7 1 8}$ & 3.44 & $00: 05: 50$ & $83.57 \%$ & $45.82 \%$ \\
\hline
\end{tabular}


Table 1: Statistics on domestic web access

\begin{tabular}{|c|c|c|c|c|c|c|}
\hline & Country/Territory & Visits & Pages/Visit & $\begin{array}{l}\text { Avg. Time on } \\
\text { Site }\end{array}$ & $\%$ New Visits & Bounce Rate \\
\hline 1. & $\underline{\text { United States }}$ & 24,724 & 2.69 & $00: 04: 31$ & $66.41 \%$ & $49.21 \%$ \\
\hline 2. & Canada & 391 & 2.56 & $00: 03: 13$ & $76.73 \%$ & $55.75 \%$ \\
\hline 3. & India & 294 & 2.30 & $00: 03: 47$ & $80.61 \%$ & $58.84 \%$ \\
\hline 4. & United Kingdom & 269 & 2.34 & $00: 02: 58$ & $84.76 \%$ & $59.48 \%$ \\
\hline 5. & Germany & 164 & 2.40 & $00: 03: 24$ & $73.78 \%$ & $57.93 \%$ \\
\hline 6. & Australia & 155 & 1.81 & $00: 02: 20$ & $87.10 \%$ & $67.10 \%$ \\
\hline 7. & Japan & 126 & 2.38 & $00: 03: 12$ & $59.52 \%$ & $48.41 \%$ \\
\hline 8. & Brazil & 116 & 2.04 & $00: 02: 25$ & $53.45 \%$ & $62.07 \%$ \\
\hline 9. & Spain & 116 & 2.84 & $00: 03: 44$ & $87.07 \%$ & $49.14 \%$ \\
\hline 10. & Croatia & 110 & 1.73 & $00: 01: 50$ & $49.09 \%$ & $72.73 \%$ \\
\hline
\end{tabular}

Table 2: Statistics on international web access

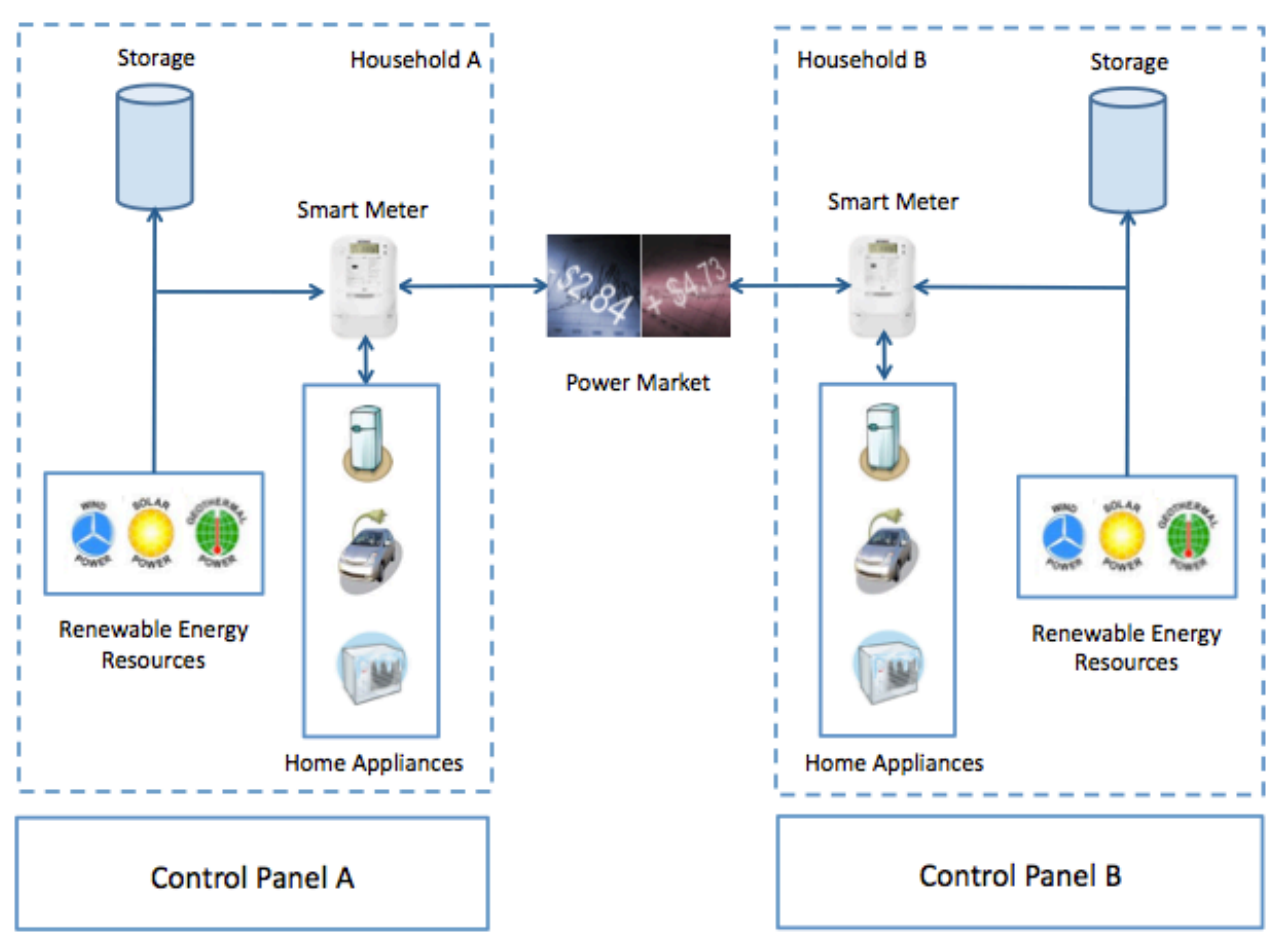

Fig. 5 A sketch of the applet interface for students A and B to interact with each other. 


\section{References:}

[1] TCIPG Education Home [Online]. Available: http://tcipg.mste.illinois.edu

[2] J. E. Tate, J. Sebestik, and T. Overbye, "Collaboration and dissemination efforts related to pre-university power lessons," in Proc. 2008 Power and Energy Society General Meeting, Pittsburg, PA, July 2008.

[3] J. E. Tate, T. J. Overbye, J. Sebestik, and G. C. Reese, "Interactive Lessons for PreUniversity Power Education," IEEE Trans. Power Syst., vol. 23, no. 3, pp. 824 -830, Aug. 2008.

[4] A. A. Renshaw, J. H. Reibel, C. A. Zukowski, K. Penn, R. O. McClintock, and M. B. Friedman, "An assessment of on-line engineering design problem presentation strategies," IEEE Trans. Educ., vol. 43, no. 2, pp. 83-91, May 2000.

[5] J. A. Nestor, "Experience With the CADAPPLETS Project," IEEE Trans. Educ., vol. 51, no. 3, pp. 342-348, 2008.

[6] Y. E. Kim, T. M. Doll, and R. Migneco, "Collaborative Online Activities for Acoustics Education and Psychoacoustic Data Collection," IEEE Trans. Learning Technol., vol. 2, no. 3, pp. 168-173, 2009.

[7] M. B. McGrath and J. R. Brown, "Visual learning for science and engineering," IEEE Comput. Graph. Appl., vol. 25, no. 5, pp. 56 -63, Sep. 2005.

[8] R. E. Mayer, "Should There Be a Three-Strikes Rule Against Pure Discovery Learning?: The Case for Guided Methods of Instruction," American Psychologist, vol. 59, no. 1, pp. 14-19, Jan. 2004.

[9] D. Leutner, "Guided discovery learning with computer-based simulation games: Effects of adaptive and non-adaptive instructional support," Learning and Instruction, vol. 3, no. 2, pp. 113-132, Jan. 1993.

[10] Project Lead the Way, (2012, Jan. 10). PLTW | STEM Education Curriculum for Middle and High Schools [Online]. Available: http://www.pltw.org 